\title{
ENERGY INFORMATION
}

ET』USS

\section{and LAWS}

Translation of the first chapter of the book

La unión hace la ciencia: un puente entre las ciencias sociales y naturales para demostrar de qué estamos hechos. Agustín Leonardo Lujan [et al.].

Dirigido por Agustín Leonardo Lujan. Editado por Alejandro Marnetti.

Editor literario: Carolina Cusa. Ilustrado por Paula Minotto. Prólogo de Diego Andrés Golombek.

1a ed.- Mendoza: Agustín Leonardo Lujan, 2021.

192 p.; il. ; 21 x $15 \mathrm{~cm}$.

ISBN 978-987-86-7909-9

1. Ciencias Naturales. 2. Ciencias Sociales y Humanidades.

I. Lujan, Agustin Leonardo, dir. II. Marnetti, Alejandro, ed.

III. Cusa, Carolina, ed. Lit. IV. Minotto, Paula, ilus.

V. Golombek, Diego Andrés, prolog.

CDD 306.45 "La unión hace la ciencia” Un puente entre las ciencias sociales y naturles para demostrar de qué estamos hechos 
to the lawyers

of my family.

Especially my father and my brother.

LUIS SEGUNO MAYORGA

Doctor in Biochemistry. I like to research

and teach. I would rather know less and

understand more. I'm bored having fun. It

amazes me that the universe sees itself

through a bubble made of its own mud. I

love my family, my friends, my mountains.
Edward Wilson, in his book Consilience (Wilson, 1999), proposes a unity of knowledge that encompasses all the sciences, from physics and chemistry to the humanities and even art. Energy management is a good example where they can be concatenated, following a fairly intuitive reasoning, from the behavior of large and small physical systems to the natural origin of ethical principles and the need for laws in today's complex human societies. This chapter tries to make this journey very succinctly, where each step is barely outlined, with the ultimate goal of completing the path without losing sight of the entire route. To compensate for this short development, each step includes at least one reference for the curious reader.

\section{LAWS OF THERMODYNAMICS}

The branch of physics that studies energy and energy changes in systems is called thermodynamics and its principles are valid in all areas of this science despite having been developed prior to the most modern branches of physics, such as relativistic physics or quantum physics.

Used to the complex scenarios of modern physics, it is surprising how simple the laws of thermodynamics are and the impressive consequences they have for all systems, living or inorganic, giant like a star or tiny like a cell. The laws are simple to state and understand at the level required for this chapter. 


\section{First Law.}

\section{Energy conservation}

This first law is not so obvious, but we are so used to hearing it that it is already familiar to us. The law says that the energy of a system cannot be generated or destroyed, and can only be changed if the system gives or receives energy from its surroundings. A thermos will keep hot or cold water for all eternity, unless it exchanges heat with its surroundings < which is what always happens; there is no perfect thermos >.

\section{Second Law.}

\section{Increased probability}

The second law is the opposite, it is very easy to understand intuitively, but we have been told about it with so much mystery that we think it is very difficult to grasp. In short, it says that every system evolves to more probable states. Our minds are well adapted to handling probabilities, and we do not find this statement bizarre or surprising. After all, if the conditions are right for it to rain, we carry an umbrella. If we drop a deck of cards from a second story, we don't expect them to be in order when we pick them up. The dense clouds will finally unload the predicted downpour and the scattered cards will be in the most absolute disorder.

\section{Order versus disorder in nature}

Let's go back to the case of cards. Why do we think they will be messy? Is it that the disorder has some privilege over order? None. Only if we list all the possible ways in which the cards of a Spanish deck can be placed (48 different cards) it gives us the gigantic sum of $12 \times 1060<a 12$ followed by 60 zeroes! $>$. Now let's think, of those different ways of arranging the cards, how many do we consider ordered? Maybe about 10 , or maybe 100 or exaggerating 1000 . Well then there are $12 \times 1057$ ways to fall messy and only 1000 to fall ordered. The conclusion is general, disordered states are much more likely than ordered ones. According to the Second Law, then, everything tends to disorder, which is a frequent used statement <and quite depressing > to describe this Law. This statement justifies what we observe with our cabinets, desks and files, which have a strong tendency to become disordered, but it goes against the striking appearance of order -in certain circumstances- in our environment.

We find order in the exquisite hexagonal symmetry present in snowflakes. An analysis of these structures tells us why they are ordered. For a water molecule to form a bond with another water molecule, it must do so at a certain angle and with a certain orientation. The union releases energy that generates disorder in the nearby molecules. Ultimately, to release energy, crystals have to grow in a certain order, dictated by the structure of the molecules involved.

However, surprisingly, we also find order in other types of circumstances that do not seem to be associated with the presence of symmetries that force an order. For example, there is order in the parallel grooves that form the cirrus clouds in the sky, in the eddies formed by water in a stream, in the spirals of a hurricane and, in general, when there is a marked imbalance between the parts of a system. The laws of thermodynamics show that every system tends to equilibrium where the flows of matter and energy cease, because the components of the system are located in their most probable positions. Precisely, the order out of balance arises when organized flows of matter and energy tend to eliminate imbalances efficiently. When the system approaches equilibrium these structures become disorganized and disappear. Strikingly, this is the type of order that living beings present. 

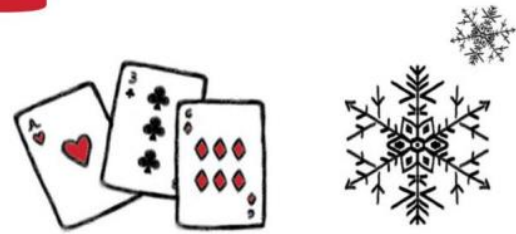

Thermodynamics tells us that everything tends towards the most probable. In many cases, this translates into a tendency to disorder, like the one shown by the cards in the image. However, sometimes order is more likely, such as when conditions are set for ice crystals to grow with a very particular hexagonal symmetry. The order appears spontaneously also when intense flows of matter and energy are produced that promote the appearance of dissipative structures capable of making energy flows more efficient, "dissipating" the imbalances that originate them. Such is the case of hurricanes that strive to compensate the acute pressure differences generated by the rise of hot air near the sea surface.

The order that arises out of equilibrium, both in inorganic structures and in living beings, requires a constant flow of energy. If we take a crystal, enclose it in a completely insulated container so that it cannot exchange energy with the environment, and observe it after a million years, the crystal will retain its structure. None of the other out-of-equilibrium ordered systems would stand up to this test. If we enclose a whole river in the container, the eddies will disappear when all the water accumulates in the lowest part of the river. If, on the other hand, we consider a living being, it will die when its food source is consumed. For this reason, we assure that this second type of order depends on a continuous flow of energy. In the terminology of Prigogine (1983), the ordered structures that are organized out of equilibrium and that tend to dissipate some energy gradient are called dissipative structures $<$ tend to eliminate imbalances>; and living organisms are an example of the extraordinary complexity that these entities can achieve.

\section{LIFE, ORDER AND INFORMATION}

Living beings are then highly ordered systems, but to maintain this order they need a constant flow of energy. On our planet there are marked imbalances produced by the continuous bombardment of light that reaches us from the sun, or by the heat that arises from the deep layers of the planet. Living beings are ordered structures that channel the flow of energy that tends to eliminate the disequilibrium that these energy sources cause on the planet.

\section{Second law, order, and information, three closely related concepts}

Our daily experience tells us that order and information are related. Our closet or desk may seem cluttered, but we have information on how to locate each thing. For a person without information, finding a certain piece of paper on our desk would mean searching everywhere for it. We can locate it quickly because we remember where we put it or when we last saw it. <although sometimes we seem like people without information from our own desks>.

In addition, from information we can generate order. If we know precisely how we want to order a deck of cards, we simply select the cards from the pile in the proper order to finally leave them exactly in one of the $12 \times 10^{60}$ possible ways to arrange the cards. $<$ a very accessible introduction to these concepts can be found in the popular book by Ben-Naim (2010)>.

\section{Information in living beings}

Living things are complex and highly ordered dissipative structures. For a living being to avoid death, order is as fundamental as energy; If we put a living being in the blender, even if it has the same components as before being blended, that system will not organize itself spontaneously and will lose all the functions of a living being. This is unlike other dissipative structures that arise spontaneously when energy gradient conditions are right, such as a whirlpool or a hurricane.

If the components of a living being do not organize themselves spontaneously, how does order arise in these systems? To answer this question, let us first remember that all living things 
are made up of cells. So, if we know how order arises in cells, we will have taken an important step in understanding order in all living beings. Fortunately, Cellular and Molecular Biology has unraveled this mystery in considerable detail (De Robertis and Hib, 2012).

Cells are exquisitely ordered machines with nanometer-scale components. Today we know that the organization of a cell is encoded in the information contained in its deoxyribonucleic acid (DNA). There the way to synthesize macromolecules $<$ like other nucleic acids and proteins> required for the organization of the cell structure is encoded. They also encode the way to regulate each of the cellular functions, such as eating, sending a message to other cells, fleeing, duplicating, and even dying.

Therefore, the cellular order is not spontaneous; it arises from a very complex instruction compiled in the DNA. Every cell needs energy to survive.<because your organization cannot be sustained without a continuous flow of energy $>$ and information <to direct that flow of energy to support your vital functions>.

The absolute requirement of information is at the base of some of the central laws of biology. For example, there is no spontaneous generation of life and every living being comes from another living being. These two postulates are explained because only living beings contain information to generate another living being. No matter how rich an environment is in energy, if there is no living being with the right information, life will not arise.

On the other hand, if there is an adequate energy source and the information to organize a living organism that can take advantage of this energy, the emergence of life will be inevitable. <not a rare and random phenomenon>. On our planet, what is difficult is to prevent our food from being filled with fungi and bacteria. Living beings crowd in the highest of the mountains and in the depth of the sea.
Figure 2 Energy source + Information = Life.

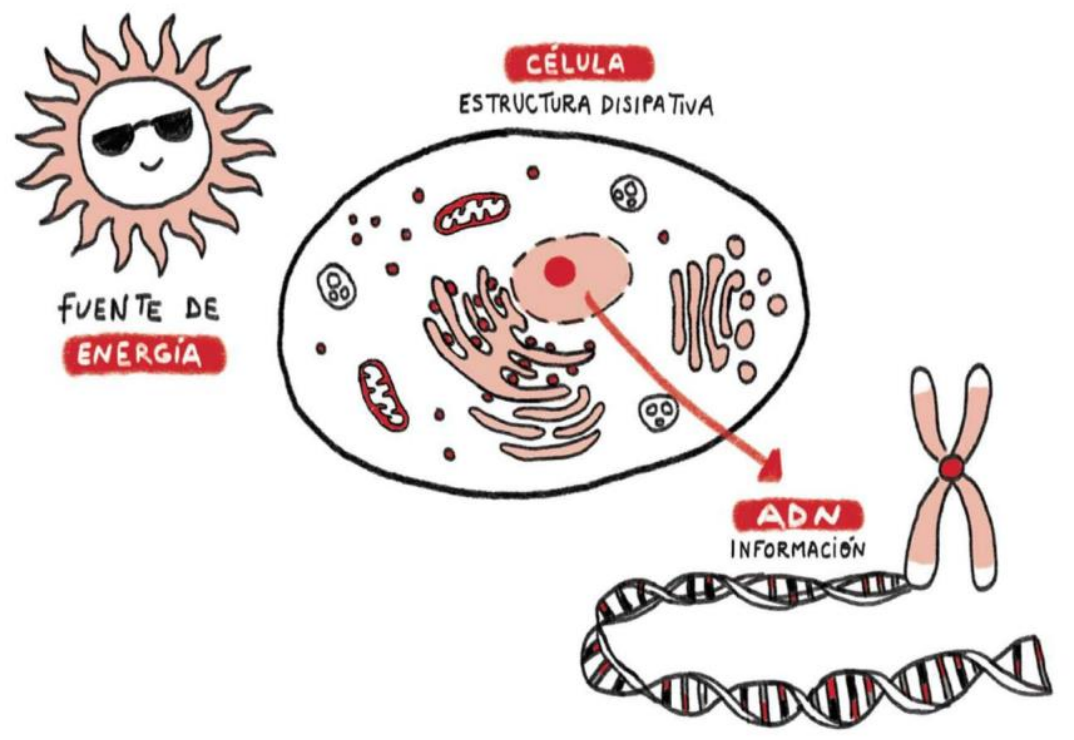

The sophisticated organization of cellular elements allows them to use the flow of energy provided by the environment (in the form of light or food) to survive and reproduce. This dissipative structure does not arise spontaneously, like a hurricane, but is organized using the information encoded in the form of genes in the molecules of the DNA. 


\section{The struggle for life}

The wonder of life does not end after the necessary information has been compiled to build a complex dissipative structure that uses the energy imbalances of our planet to survive and reproduce.

This is only a first step, because the ability to reproduce and replicate the information contained in their DNA makes living beings to expand until some element in the environment, necessary for life, becomes limiting. Therefore, the options are to go extinct or change the information in their DNA to somehow survive and reproduce. The necessary conditions are then given for what is called natural selection to occur; the evolutionary process that has so much influenced the improvement of survival strategies of living beings. <a very accessible book on evolution is by Larson (2007)>. The scenario for natural selection could be summarized as follows:

1- In a given environment, living things compete for some scarce good that limits their ability to reproduce.

2- Living beings have encoded in their DNA the information necessary for their organization as a dissipative structure, but also with the ability to compete for scarce resources and transmit this information when reproducing. The information contained in the genome can then be considered a survival strategy.

3-Information transmission is not perfect, so variations occur that can modify survival efficiency and eventually improve it.

4- Of the set of variants that are generated, only those that contain the information that encodes for a winning strategy survive.

Note that, in this scenario, the two elements that justify the appearance of ordered structures according to thermodynamics are maintained. On the one hand, it must always be present the energy imbalance or source of energy, without which life is extinguished. On the other hand, information comes into play to organize a living being that uses this energy gradient and is proficient to compete for whatever the scarce and limiting element is (which may be, precisely, the energy source).

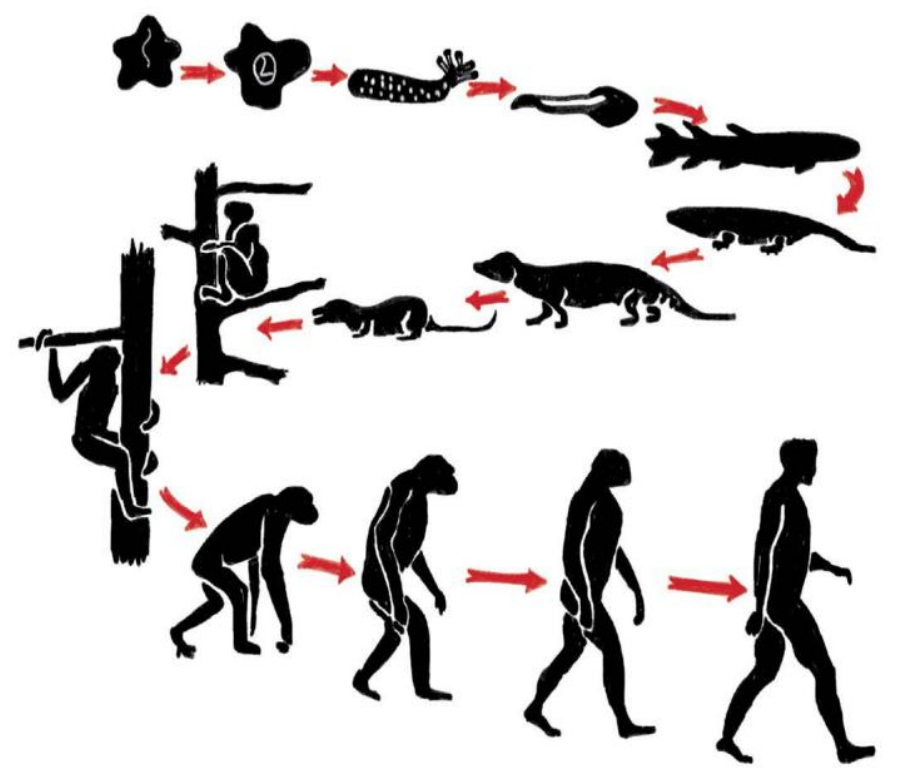

The information contained in DNA codes for an organism that needs to compete with other organisms to survive and reproduce. Evolution, through innumerable cycles of random changes and selection, modifies the initial information and guides organisms in their adaptation to the environment in which they live. 


\section{Societies of living organisms}

Survival imposes a ruthless selection of information that is passed on to offspring. If the information is in a losing context, it disappears. It is then reasonable that the information contained in the DNA tends to perpetuate itself and justifies the concept of the selfish gene (Dawkins, 1993). That is: genes seek to provide reproductive advantages for the individual that hosts them because they are interested in being inherited by an increasing number of organisms. Actually, you don't have to think about ethical connotations among genes. Those who succeed with a good strategy in the tough competition to survive, endure.

The pressure is so strong that the genes assemble strategies that exploit the most unexpected mechanisms so that, somehow and somewhere, the information is transmitted and the gene endures. It is not surprising, then that cooperation between organisms arose among the strategies. If several organisms help and complement each other so that they can be successful in transmitting to their offspring the genes that are part of this cooperation, then these altruistic genes they will be preserved. However, this has one condition: the organisms must share genes. In this way the successful survival of the group would guarantees the expansion of altruistic genes. This principle is what has allowed the emergence and expansion of multicellular organisms. All cells in an organism share the same genes. It is also the basis for complex insect societies, such as ants, where all individuals share maternal genes.

All this leads us to wonder if the appearance of cooperativity and altruistic genes can occur between individuals who do not share the same genes. At first, it seems so. It is not difficult to think of cooperative attitudes that allow all individuals in a group to benefit, so that all genes in the group can expand. The problem is that if genes are not shared, an individual who does not cooperate, who takes advantage of the group, will have an advantage over the rest: he will receive all the benefits and contribute nothing, which will ultimately give him a winning strategy and he will produce more offspring <what opinion would you have of that individual? Remember it, because it will be important in the sections that follow>. According to various mathematical models with which these problems are studied, after a while, individuals who do not cooperate will be selected and the altruistic genes will disappear. However, if the group can identify the uncooperative individual and exclude him, his genes will not flourish and the advantages that the altruistic genes confer on the group will promote the expansion of these genes.

In short, genes have a selfish basis dictated by the need to pass on to offspring. Anything goes for the organism that houses them to survive and reproduce. However, some genes achieve better survival, even at the cost of some sacrifice of the living being that contains them <altruistic genes>, only if they promote the success and reproduction of other organisms, carrying the same genes. Alternatively, they can prevail if they promote the success of various organisms that help the survival of the living being that houses them. In the latter case, it is imperative to be able to detect and exclude organisms that do not carry the altruistic genes and cheat the group.

\section{Figure 4 Cooperating can also be a winning strategy.}

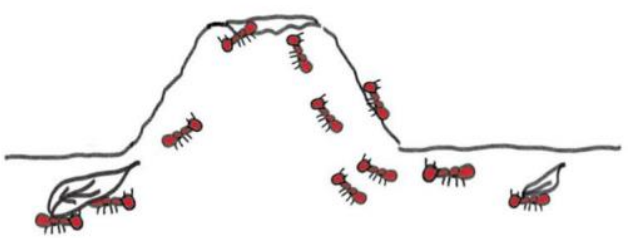

The cells of a multicellular organism have developed a complex set of altruistic genes that allow the specialization of different cell types that collaborate with each other to achieve the survival of the whole. A cancer would be a set of cells that have lost some of these altruistic genes and reproduce regardless of the final fate of the host organism. Social insects like ants follow the same principle observed in the cells of multicellular organisms. Each caste works to ensure that the queen survives and she is the only one that generates the eggs that ensure the reproduction of the species. 


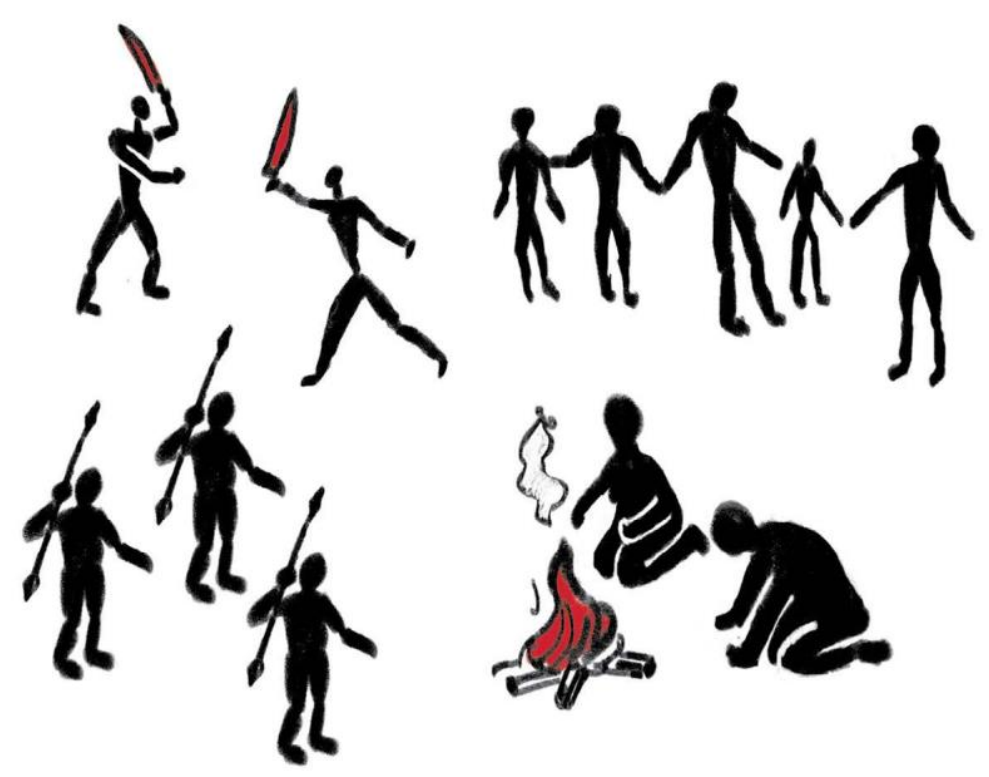

Human beings carry in our genes a set of altruistic attitudes towards the members of our tribe, which are the basic substrate of our ethical principles. A tribe formed by individuals who value these principles will have an advantage for survival and reproduction. However, altruistic behaviors are limited to the members of the tribe. For those of the other tribes there will only be indifference if their presence does not threaten us, or aggressiveness if they constitute a rival group.

\section{Information and organization of human groups: modern societies}

Complex modern societies evolved with the advent of agriculture and the domestication of animals in a relatively very short period of time, no more than 10,000 years ago. <remember that the Earth is over 4.500 million years olds.
The set of individuals encompassed in these societies was much larger than a tribe. The behavioral bases written in our genes no longer covered all the aspects that need to be considered for the proper functioning of a city, a group of cities or a nation. Nevertheless, selective pressure was still present; weak cities disappeared, weak nations were absorbed by other nations. Altruistic ethical sentiments within the group and defense against rival groups continued to be fundamental in the struggle to survive, but it was necessary to generate behavioral norms to organize these increasingly complex societies. The necessary rules are no longer codified in our genes; they are written in the laws, which are then a new source of information that defines the organization of a society.

It is interesting to see how our altruistic and xenophobic attitudes complement each other and sometimes conflict in today's world. In the first place, it is easy to realize that each one of us belongs to numerous groups and therefore altruistic feelings of collaboration and generosity arise from within us, which are mixed with attitudes of indifference or aggressiveness towards groups to which we do not belong. The intricate interconnected web between the groups with which we identify, ranging from our family, work, religion, sexual orientation, race, political party, province, nation, even our soccer team, generates a mixture not without conflicts between our altruistic and selfish tendencies. We individuals then move between feelings that move us towards ethical conduct <within the structure to which we belong $>$ and unethical conduct <against members of rival structures $>$. To justify our selfish attitudes, it is enough to think that those we attack belong to some rival group. If we act within the law, we will seek to benefit our group as much as possible, regardless of whether the rival group is abused. The laws, however, exclude <or should exclude> these discriminations between the different groups that make up a society. They are equal and valid for all. In the same way, the laws must respect and order the ethical principles inscribed in our genes; there can be laws in conflict with human nature. 


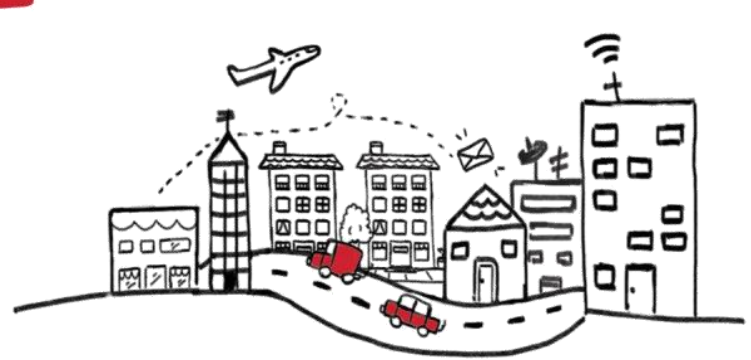

The information contained in our genes is not enough to order a modern society. Supplementary information is needed that is codified in our laws, which mark what individuals in a complex society can and must do.

\section{CONCLUSIONS}

The laws of thermodynamics allow the emergence of ordered structures in systems in equilibrium <crystals> and in non-equilibrium systems <hurricanes>. The origin of the order in both cases has different causes; in the first, it is dictated by the symmetries of the elements that compose them, in the second in the emergence of dissipative structures that facilitate the flows of matter and energy that necessarily occur in the search for balance.

If we think of systems far from equilibrium, we observe that the order in natural phenomena arises spontaneously, but in living beings, it arises from the information encoded in their genes. One mystery not addressed in this chapter is how the information needed to generate the first cell was compiled. However, with the energy available on the planet and the information encoded in the genes, life is not something eventual and improbable; quite the contrary, it is inevitable.
However, the information has not been passively passed down through the generations. In the fantastic survival game, selective pressure has made living beings explore the most diverse strategies that make up the gigantic set of current and extinct species.

The information encoded in the genes also explored the manipulation of the behavior of individual organisms in order to generate associations that maximized the chances of survival and reproduction. The human race is located in this branch of strategies, in whose genes are encoded altruistic attitudes, indifference, and aggressiveness that allowed Homo sapience to survive in successful tribes over many thousands of years.

For the organization of modern society, the information contained in our genes is not enough. The need arises for rules that are now codified in laws necessary to organize societies more complex than the tribe.

Finally, in order to achieve the organization of a sustainable dissipative structure on planet earth that encompasses all of humanity, laws that have not yet been drafted and that are unfortunately difficult to agree on $<$ given the natural selfishness of the prevailing power groups $>$ will be needed. Science $<$ note that I am talking about science and not scientists $>$, with its rational and neutral nature, with its ability to model possible scenarios and with unbiased handling of information, would be a key piece in the search of laws that promote a world where the ethical principles inscribed in our genes are applied to all humanity. 
Wilson, Edwards O. (1999). Consilience. The unit of knowledge. Trad. by Joandoménec Ros. Barcelona, Spain: Galaxy, Gutenberg.

Prigogin llya (1983). Just an illusion? An exploration from chaos to order.Trad. by Francis Martin. Barcelona, Spain: Tusquets Editores S.A.

Ben-Naim, Arieh (2010). Discover entropy and the second law of thermodynamics: a playful way of discovering a law of nature.

London, UK: World Scientific Publishing Co.

DeRobertis, Edward; Hib, Jose (2012).Cellular and Molecular Biology of De Robertis (16th Ed.). Buenos Aires: Avg.

Larson, Edward J. (2006). Evolution. The amazing story of scientific Theory Trad. by Mercedes Garcia Garmill. Barcelona, Spain: Debate.

Dawkins, Richard (1993). The selfish gene: the biological bases of our behavior (3rd Ed.). Trad. by Juana Robles Suarez.

Barcelona, Spain: Salvat Editores S.A. 